\title{
Erratum to: The altered gut microbiota in adults with cystic fibrosis
}

\author{
D.G. Burke ${ }^{1,2}$, F. Fouhy', M. J. Harrison ${ }^{3,4}$, M. C. Rea ${ }^{1,2}$, P. D. Cotter ${ }^{1,2}$, O. O'Sullivan ${ }^{1,2}$, C. Stanton ${ }^{1,2}$, C. Hill ${ }^{2,5}$, \\ F. Shanahan ${ }^{2,6}$, B. J. Plant ${ }^{2,3,4,6}$ and R. P. Ross R. $^{2 *}$
}

\section{Erratum}

In the original manuscript [1] there was a mislabelling of the data resulting in Actinobacteria and Bacteroidetes at phylum level being switched. This has been corrected in the amended Figs. 2 and 4 below where before you had high levels of Actinobacteria; these are now corrected to Bacteroidetes. These amended figures show that there was a significant $(p<0.05)$ decrease in the relative abundance of Actinobacteria, Proteobacteria, Cyanobacteria, Verrucomicrobia, RF3, Tenericutes, and Lentisphaerae in individuals with $\mathrm{CF}$ at the phylum level, relative to the non-CF controls (Fig. 2). Notably, there was a significant $(p<0.05)$ increase in Firmicutes in people with CF relative to the controls ( $47 \%$ vs. $39 \%$ respectively). The overall conclusions in the manuscript remain unchanged.

\footnotetext{
Author details

${ }^{1}$ Teagasc Food Research Centre, Cork, Ireland. ${ }^{2}$ APC Microbiome Institute, Cork, Ireland. ${ }^{3} \mathrm{HRB}$ Clinical Research Facility, University College Cork, Cork, Ireland. ${ }^{4}$ Cork Cystic Fibrosis Centre, University College Cork, Cork University Hospital, Cork, Ireland. ${ }^{5}$ School of Microbiology, University College Cork, Cork, Ireland. ${ }^{6}$ Department of Medicine, University College Cork, National University of Ireland, Cork, Ireland. ${ }^{7}$ College of Science, Engineering and Food Science (SEFS), University College Cork, Cork, Ireland.
}

Received: 11 April 2017 Accepted: 11 April 2017

Published online: 27 April 2017

\section{Reference}

1. Burke DG, Fouhy F, Harrison MJ, Rea MC, Cotter PD, O'Sullivan O, Stanton C, Hill C, Shanahan F, Plant BJ, Ross RP. The altered gut microbiota in adults with cystic fibrosis. BMC Microbiol. 2017;17(1):58.

\footnotetext{
* Correspondence: p.ross@ucc.ie

${ }^{2} \mathrm{APC}$ Microbiome Institute, Cork, Ireland

${ }^{7}$ College of Science, Engineering and Food Science (SEFS), University College Cork, Cork, Ireland
} 

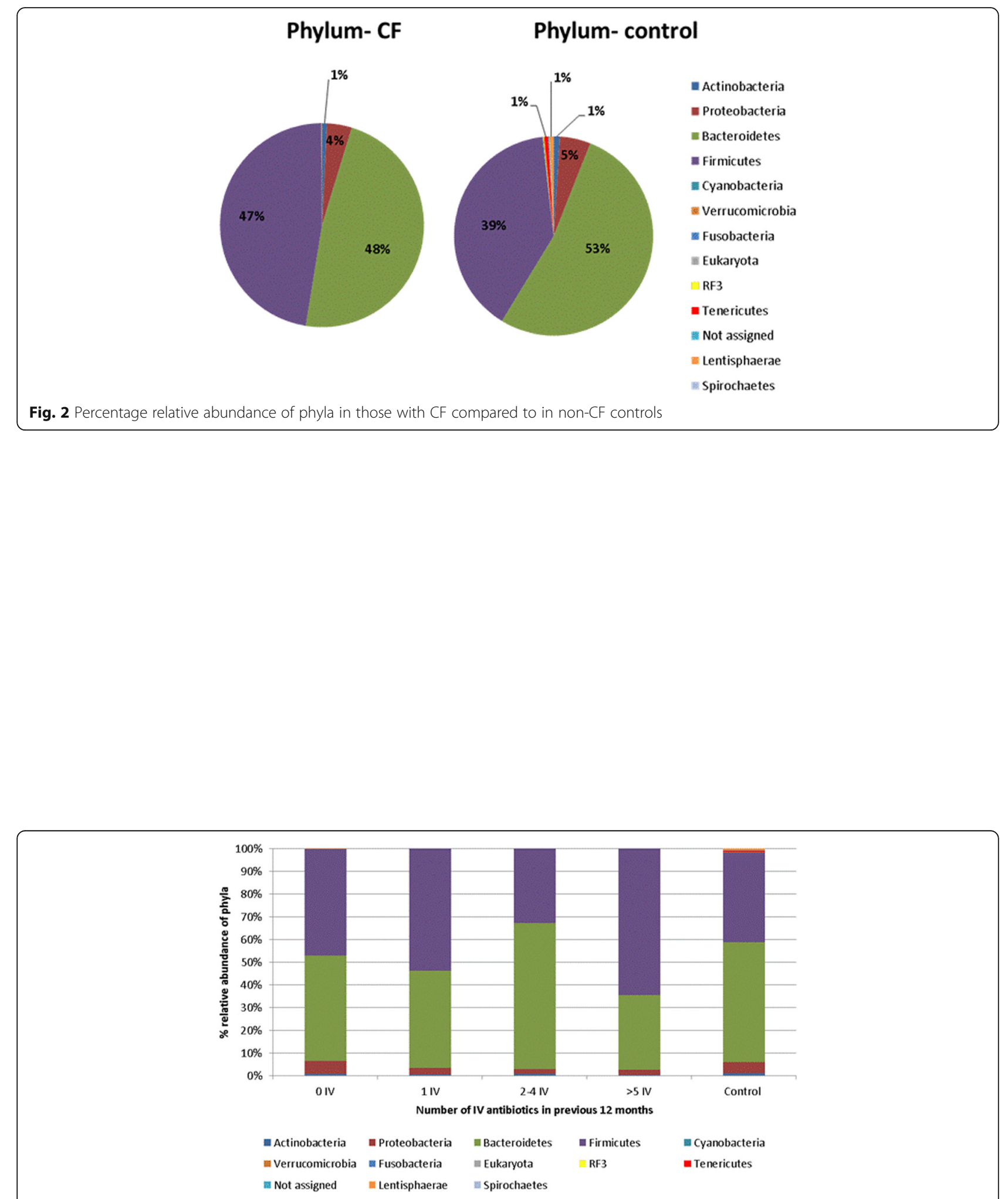

Fig. 4 Percentage relative abundance of phyla in the non-CF controls compared to the individuals with CF, stratified based on number of IV courses in the previous 12 months 